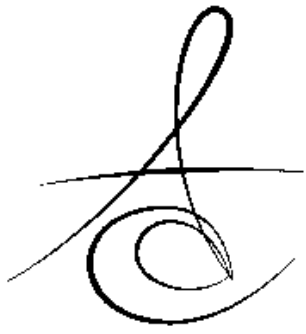

\title{
FARKLI BEYAZLATMA YÖNTEMLERİ UYGULANMIŞ DİŞLERİN RENKLENMESİNDE KIRMIZI ŞARABIN ETKİSİ
}

\section{THE EFFECT OF RED WINE ON DISCOLORATION OF TEETH BLEACHED USING DIFFERENT BLEACHING METHODS}

\author{
Yrd. Doç. Dr. Muhammet KARADAŞ* $\quad$ Yrd. Doç. Dr. Sezer DEMİRBUĞA** \\ Arş. Gör. Dt. Nazire Nurdan ÇAKIR ${ }^{*}$
}

Makale Kodu/Article code: 2856

Makale Gönderilme tarihi: 18.05 .2016

Kabul Tarihi: 28.12.2016

\section{öz}

Amaç: $\mathrm{Bu}$ in vitro çalışmanın amacı, farklı yöntemlerle beyazlatma yapılmış dişlerin renklenmeleri üzerine kırmızı şarabın etkisini değerlendirmektir.

Gereç ve Yöntem: Sığır keser dişlerinden mine-dentin örnekleri elde edildi. Örnekler, beyazlatma yöntemlerine göre rastgele dört gruba ayrıldı: (1) Ofis tipi beyazlatma, (2) Ev tipi beyazlatma, (3) Beyazlatma stripleri, (4) Kontrol grubu $(n=10)$. Beyazlatma ajanları üretici firmaların belirlediği sürelerde örneklere uygulandı. Beyazlatma işleminden sonra örnekler iki alt gruba ayrıldı. Birinci alt gruptaki örnekler beyazlatma işlemlerinden hemen sonra, ikinci alt gruptaki örnekler 48 saat sonra 4 saat boyunca kırmızı şarap içinde bekletildi. Renklendirme işleminden sonra örneklere polisaj yapıldı. Renk ölçümü spektrofotometre ile beyazlatma işleminden önce, beyazlatma işleminden sonra, kırmızı şarapta bekletme işleminden sonra, polisaj işleminden sonra gerçekleştirildi. Veriler CIELAB ( $\left.{ }^{*} a * b *\right)$ sistemine göre kaydedildi. Elde edilen veriler istatistiksel olarak tek yönlü ANOVA ve Tukey testi ile analiz edildi $(p<0.05)$.

Bulgular: Ev ve ofis tipi yöntemin beyazlatma etkinliği beyazlatma striplerinden önemli ölçüde daha fazlaydı $(p<0.05)$. Beyazlatma sonrası bekleme süresine bakılmaksızın ofis tipi beyazlatma ajanı ve beyazlatma stripleri uygulanan örnekler kontrol grubundaki örneklerden önemli derecede daha fazla renklendi $(p<0.05)$. Ev tipi beyazlatma ve kontrol grubu arasında dişlerin renklenmesi açısından önemli bir farklılık bulunamadı $(p>0.05)$. Polisaj işlemi beyazlatılmış örneklerin renklenme derecesini önemli derecede azalttı. Polisaj işleminden sonra gruplar arasında önemli bir farklıık bulunamadı ( $p>0.05$ ).

Sonuçlar: Beyazlatma tedavilerinden sonra bekleme zamanı dişlerin renklenme derecesini etkilemedi. Farklı beyazlatma metotları ve beyazlatmadan sonra yapılan polisaj işlemi dişlerin renklenme derecesini etkileyebilir.

Anahtar kelimeler: Ev tipi beyazlatma, ofis tipi beyazlatma, beyazlatıcı strip, diş renklenmesi

\section{ABSTRACT}

Aim: To evaluate the influence of red wine on discoloration of teeth bleached using different bleaching methods.

Material and Method: The enamel-dentin samples were obtained from bovine incisors. Then teeth were randomly divided into four groups: (1) In-office bleaching, (2) Home-bleaching, (3) Whitestrips, and (4) Control group (unbleached, $n=10$ ). Whitening agents were applied to the samples in the time that their manufacturers specify. After bleaching treatments, the samples in each group were divided into two subgroups. The samples in first subgroup were immersed in red wine for $4 \mathrm{~h}$ immediately after bleaching. The samples in second subgroup were immersed in red wine for $4 \mathrm{~h} 48 \mathrm{~h}$ after bleaching. After staining, the samples were polished. The color was measured using spectrophotometer before and after bleaching, after staining, and after polishing the stained samples. Data were recorded based on the CIELAB (L*a*b*) system. Data were analyzed by One-Way ANOVA, followed by Tukey's test $(p<0.05)$.

Results: The whitening effect of the home bleaching and in-office bleaching was significantly greater than that of the whitestrips $(p<0.05)$. The level of staining of the samples bleached by in-office bleaching and whitestrips was significantly higher than that of the unbleached group $(p<0.05)$ regardless of the waiting time after bleaching. No significant difference in tooth discoloration was found between the home-bleaching and control group $(p>0.05)$. The polishing process reduced significantly the degree of staining on the bleached samples. After polishing, there were no significant differences in staining among all the groups ( $p>0.05)$.

Conclusions: After bleaching treatments, the waiting time did not affect the degree of staining of teeth. The different bleaching methods and post-bleaching cleaning procedures can affect the degree of tooth discoloration.

Keywords: Home-bleaching, in-office-bleaching, whitestrip, tooth discoloration

\footnotetext{
*Recep Tayyip Erdoğan Üniversitesi, Diş Hekimliği Fakültesi, Diş Hastalıkları ve Tedavisi AD

**Erciyes Üniversitesi, Diş Hekimliği Fakültesi, Restoratif Diş Tedavisi ve Endodonti AD
} 
Atatürk Üniv. Diş Hek. Fak. Derg.

J Dent Fac Atatürk Uni

Cilt:27, Sayı:2, Yıl: 2017, Sayfa, 73-78

\section{GİRIŞ}

Diş beyazlatma konservatif ve etkili bir tekniktir ve estetik diş hekimliğinin önemli bir komponenti haline gelmiştir. ${ }^{1}$ Peroksit içerikli beyazlatma ürünleri dişlerin beyazlatılması için en etkili ajanlardır. Hidrojen peroksit (HP) konsantrasyonu uygulanan beyazlatma prosedürüne bağlı olarak değişir. ${ }^{2,3}$ Vital diş beyazlatma yöntemleri üç temel beyazlatma yaklaşımını içerir: ev tipi beyazlatma sistemi, ofis tipi beyazlatma ve over the counter (OTC) (marketlerde satılan, hasta tarafından uygulanan) beyazlatma yöntemi. Ev tipi beyazlatmada karakteristik olarak beyazlatma ajanı dişlere fabrikasyon bir plak aracılığıla nispeten daha düşük seviyede en az iki hafta boyunca geceleri uygulanır. Ofis tipi beyazlatma ajanları ev tipi beyazlatma ajanlarından daha yüksek konsantrasyonda ve daha kısa süre uygulanır. OTC ürünleri iki hafta boyunca günde iki kez daha düşük seviyelerde beyazlatma ajanı emdirilen polietilen stripler aracılığıyla hastaların kendi kendilerine uyguladığı yöntemdir. ${ }^{4,5}$

Beyazlatma ajanlarının dişleri nasıl beyazlattığı tam olarak bilinmemektedir. ${ }^{6}$ Beyazlatma ajanları organik ve inorganik renklenmiş moleküllerin yapısını değiştiren oksidasyon yoluyla diş renklenmelerini kaldırır. ${ }^{4}$ Beyazlatma ürünleri aktif bileşenleri stabil tutmak ve beyazlatma sürecini kolaylaştırmak için genellikle daha düşük $\mathrm{pH}^{\prime}$ da formüle edilmektedir. ${ }^{2}$ Peroksit içerikli ürünler beyazlatma yöntemleri ve beyazlatma ajanının pH'na bağlı olarak diş yapısındaki yüzey gözeneklerini ve yapısal geçirgenliği çeşitli derecelerde destekleyebilir. Mine yüzeyindeki değişiklikler peroksit tarafından oluşturulan oksidasyon ve demineralizasyona bağlanmaktadır. ${ }^{7}$ Bazı çalışmalar vital diş beyazlatma yöntemlerinin diş yapılarındaki gözeneklerin çaplarının artmasını ve erozyon ya da pürüzlülüğün oluşumunu indükleyebildiğini bildirmiştir.8,9

Özellikle diş yapılarında gözenekler ve yüzeysel bozukluklar olduğunda kahve, çay, meyve suyu, şarap önemli derecede diş renklenmelerine neden olabilir. ${ }^{10,11}$ Diş renklenmesinin tipinin ve derecesinin yalnızca beslenme modeline bağlı olmadığı aynı zamanda düşük $\mathrm{pH}$ koşullarınada bağlı olduğu belirtilmiştir. ${ }^{12}$ Beyazlatılmış mine yüzeyi, özellikle kırmızı şarap, kola, siyah çay gibi asitli içeceklere renklenme açısından daha duyarlı olmaktadır. Bu tür içeçeklerin tüketimi tüm dünyada oldukça popülerdir. Bu nedenle, estetik amaçlarla bu içeceklerin tüketiminin yasaklanması
KARADAŞ, DEMİRBUĞA, KÇAKIR

çoğu durumda mümkün değildir. ${ }^{13}$ Önceki bir çalışmada dişlerin tükürük içerisinde saklanmasının beyazlatma işlemi ile minede oluşan mineral kaybı ve buna bağlı oluşan porözitenin tersine çevrilebildiği bildirilmiştir. ${ }^{14}$ Bundan dolayı beyazlatma sonrası yeterince beklemek renklenmenin derecesini etkileyebilir.

Farklı diş beyazlatma yöntemleri sonrası özellikle polietilen stripler hakkında diş renklenmeleri ile ilgili çok az bilgi mevcuttur. Beyazlatma yöntemlerinin koşulları ve konsantrasyonları tedavi şekillerine göre önemli ölçüde değişir. Bu in vitro çalışmanın amacı üç farklı beyazlatma yöntemi (ofis, ev ve stripler) kulanılarak yapılan beyazlatma sonrası kırmızı şarap çözeltisinin renklenmeye etkisini değerlendirmektir, aynı zamanda beyazlatma sonrası renklenmiş dişlere polisaj uygulamasının etkisini belirlemektir.

\section{GEREÇ VE YÖNTEM}

\section{Örnek hazırlanması ve beyazlatma}

Bu çalışma için 70 adet yeni çekilmiş sığır keser dişi toplandı ve scaler yardımı ile temizlendi. Dişler dezenfeksiyon için 48 saat boyunca chloramine-T solusyon'unda bekletildi ve sonra iki hafta içinde kullanılıncaya kadar distile su içinde saklandı. Lekeli ve kırık dişler çalışmaya dahil edilmedi. Su soğutmalı elmas testere (Impect PC10; Equilam Lab Equip, Diadema, SP, Brazil) kullanılarak $5 \times 5 \mathrm{~mm}$ boyutlarında ve $3 \mathrm{~mm}$ kalınlıkta mine-dentin kesitleri hazırlandı. Mine yüzeyine beyazlatma ajanlarını uygulamak için mine-dentin kesitleri akrilik rezinin içerisine gömüldü. Mine yüzeyi polisaj fırçası ve polisaj patı kullanılarak temizlendi (1200 rpm). Örnekler beyazlatma yöntemlerine göre 7 gruba ayrıldı $(n=10)$;

Grup Ia ve Grup Ib: Opalescence Boost jeli (Ultradent Products INC, South Jordan, Utah, ABD; \% $40 \mathrm{HP}$ ) ile beyazlatılmış örnekler. Beyazlatma jeli örnek yüzeylerine $1,5-2 \mathrm{~mm}$ kalınlığında bir tabaka şeklinde uygulandı ve $37^{\circ} \mathrm{C}$ de 20 dakika boyunca örnek yüzeyinde kalmasına izin verildi. Uygulama aynı seansta üç kez tekrarlandı. Prosedür 5 gün sonra yeniden yapıldı.

Grup IIa ve Grup IIb: Opalescence PF jeli (Ultradent Products INC, South Jordan, Utah, ABD; \% $16 \mathrm{CP}$ ) ile beyazlatılmış örnekler. 14 gün boyunca örnekler günde 4 saat $37^{\circ} \mathrm{C}$ de 1,5-2 mm kalınlığında bir tabaka ile CP jeline maruz bırakıldı.

Grup IIIa ve Grup IIIb: Crest 3D beyazlatma stripleri (Procter \& Gamble, Cincinnati, $\mathrm{OH}$,

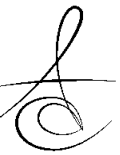


ABD; \% 9,5 HP) ile beyazlatımış örnekler. Beyazlatma stribinden elde edilen bir kesit $(6 \times 6 \mathrm{~mm}) 30$ dakika süreyle $37^{\circ} \mathrm{C}$ de örneklere uygulandı. Bu ișlem günde iki kez 14 gün boyunca tekrarlandı.

Grup IV: Beyazlatma işlemi uygulanmayan grup (kontrol grubu)

Üreticilere göre beyazlatma materyallerinin bileşimleri Tablo 1'de gösterilmiştir. Beyazlatma jelleri üreticilerin tavsiyelerine uygun olarak kullanıldı. Beyazlatma jeli pamuk rulolar ile temizlendi ve örnekler distile su ile yıkandı. Beyazlatma işlemi aralıkları süresince örnekler $37^{\circ} \mathrm{C}$ 'de günlük olarak değiştirilen yapay tükürük ${ }^{15}$ içinde saklandı.

Grup Ia, IIa, ve IIIa'da örnekler beyazlatmadan hemen sonra $37^{\circ} \mathrm{C}$ de 4 saat boyunca $100 \mathrm{ml}$ kırmızı şarap içinde bekletildi. Grup Ib, IIb, ve IIIb'deki örnekler ise beyazlatma sonrası 48 saat boyunca yapay tükürük içerisinde saklandı ve sonra $37^{\circ} \mathrm{C}$ de 4 saat boyunca kırmızı şarap içerisinde bekletildi. Örnekler kırmızı şarapta bekletildikten sonra her biri 10 saniye distile su ile yıkandı. Daha sonra mine yüzeylerine polisaj yapıldı (1200 rpm).

Tablo 1. Çalışmada kullanılan beyazlatma materyalleri.

\begin{tabular}{|l|l|l|c|}
\hline Materyal & Üretici & Bileşim & pH \\
\hline $\begin{array}{l}\text { Opalescence } \\
\text { PF \%16 }\end{array}$ & $\begin{array}{l}\text { Ultradent } \\
\text { Products INC, } \\
\text { South Jordan, } \\
\text { Utah, ABD }\end{array}$ & $\begin{array}{l}\text { Gliserin, su, xylitol, karbamid } \\
\text { peroksit, karbomer, PEG-300, } \\
\text { sodyumhidroksit, } \\
\text { potasyumnitrat, EDTA, } \\
\text { sodyumflorid }\end{array}$ & 6.5 \\
\hline $\begin{array}{l}\text { Opalescence } \\
\text { Boost \%40 }\end{array}$ & $\begin{array}{l}\text { Ultradent } \\
\text { Products INC, }\end{array}$ & $\begin{array}{l}\text { Hidrojen peroksit, florid, } \\
\text { potasyum nitrat }\end{array}$ & $\begin{array}{l}6.4- \\
\text { Utah, ABD }\end{array}$ \\
\hline $\begin{array}{l}\text { Crest 3D } \\
\text { Whitestrips- } \\
\text { advance } \\
\text { dvivid }\end{array}$ & $\begin{array}{l}\text { Procter \& } \\
\text { Gamble, } \\
\text { Cincinnati, OH, } \\
\text { ABD }\end{array}$ & $\begin{array}{l}\text { Su, gliserin, \% 9,5 hidrojen } \\
\text { peroksit, karbomer, sodyum } \\
\text { hidroksit, sodyum sakkarin }\end{array}$ & 5 \\
\hline
\end{tabular}

\section{Renk ölçümü}

Renk ölçümleri dijital spektrofotometre (VITA Easyshade Advance; Zahnfabrik, Bad Säckingen, Almanya) ile D65 aydınlatma altında gerçekleştirildi. Spektrofotometre üreticinin talimatlarına göre bir kalibrasyon bloğu kullanılarak kalibre edildi. Renk beyazlatma öncesi, beyazlatama sonrası, örnekler kırmıı şarabın içerisinde bekletildikten sonra ve polisaj işleminden sonra deneyimli bir gözlemci tarafından ölçüldü. Elde edilen ölçümler International Commission on Illumination (CIE) tarafından tanımlanan renk sistemindeki $L^{*}, a^{*}$, ve $b^{*}$ parametrelerine göre kaydedildi. Farklı zaman aralıklarında renk farkı $(\Delta \mathrm{E})$ aşağıdaki formül kullanılarak hesaplandı:

$\Delta \mathrm{E}=\left[\left(\Delta \mathrm{L}^{*}\right)^{2}+\left(\Delta \mathrm{a}^{*}\right)^{2}+\left(\Delta \mathrm{b}^{*}\right)^{2}\right]^{0.5}=\left[\left(\mathrm{L}_{2}-\mathrm{L}_{1}\right)^{2}+\right.$ $\left.\left(a_{2}-a_{1}\right)^{2}+\left(b_{2}-b_{1}\right)^{2}\right]^{0.5}$

Formülde yer alan 1 ilk ölçüm değerleri iken 2 ikinci ölçüm değerleridir. $L^{*}$ değeri parlaklı̆ı̆, a* değeri kırmızılık-yeşillik, b* değeri sarılık ve maviliği belirtmektedir.

Her bir yöntemin beyazlatma etkinliği beyazlatmadan önceki ve beyazlatmadan sonraki $L^{*}, a^{*}, b^{*}$ parametreleri kullanılarak belirlendi. Diş renklenmesi beyazlatmadan sonra ve renklendirmeden sonra ( $T 1$ ), beyazlatmadan sonra ve polisaj işleminden sonra (T2) $L^{*}, a^{*}, b^{*}$ parametreleri arasında hesaplandı.

\section{Istatistiksel analiz}

Beyazlatma yöntemlerinin etkinliği tek-yönlü varyans analizi (ANOVA) kullanılarak değerlendirildi. Renklendirme, polisaj işleminden sonraki renk değişiklikleri tekrarlanan ölçümlü analiz tekniği (ANOVA for repeated measures) ve Tukey testi ile analiz edildi.

\section{BULGULAR}

Beyazlatma sonrası, $\Delta \mathrm{E}, \Delta \mathrm{L}, \Delta \mathrm{a}$ ve $\Delta \mathrm{b}^{\prime}$ deki değişiklikler Resim 1'de sunulmuştur. Beyazlatma işlemlerinden hemen sonra, $\% 40 \mathrm{HP}$ ve $\% 16 \mathrm{CP}$ jelleri ile striplerden önemli derecede daha yüksek $\Delta \mathrm{E}$ değerleri bulundu $(p<0.05)$. Ofis ve ev tipi beyazlatma işlemleri arasındaki fark anlamlı değildi $(p=0.89)$. Ofis ve ev tipi beyazlatma yöntemleri beyazlatma stripleri ile karşılaşıırıldığında, $\Delta \mathrm{L}^{\prime}$ deki değişiklikler oldukça yüksekti $(p<0.05)$. Beyazlatma sonrası gruplar arasında $\Delta a$ ve $\Delta b^{\prime}$ deki farklılıklar istatistiksel olarak anlamlı değildi (sırasıyla, $p=0.24$ ve $p=0.40$ ).

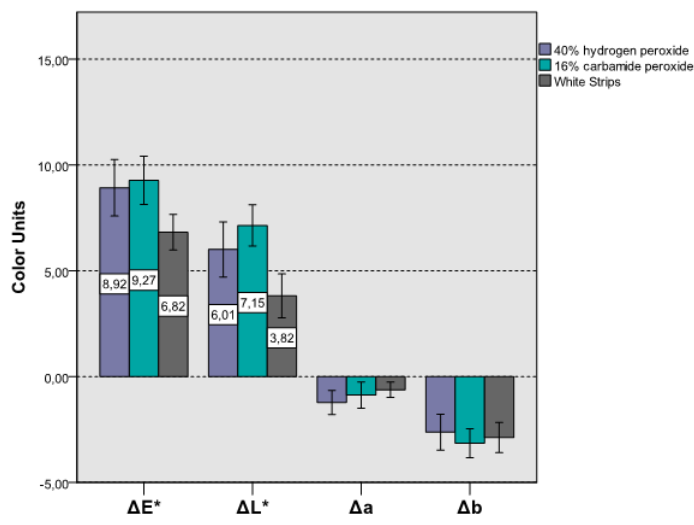

* : gruplar arasındaki anlamlı farklığı gösterir $(p<0.05)$

Figür 1. Beyazlatma tedavisinden sonra $\Delta E, \Delta L, \Delta a$ ve $\Delta b$ değerleri.

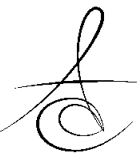


Renklendirme ve polisaj işleminden sonraki $\Delta \mathrm{E}$ ve $\Delta \mathrm{L}$ değerleri Tablo 2'de gösterilmiştir. $\% 40 \mathrm{HP}$ ve beyazlatma stripleri ile beyazlatılan örneklerin boyanması beyazlatma sonrası bekleme süresine bakılmaksIzın beyazlatma uygulanmayan örneklerden (kontrol grubu) çok daha yüksekti $(p<0.05)$. Beyazlatma sonrası bekleme süresi (hemen ve 48 saat sonra) dişlerdeki renklenmenin derecesini etkilemedi. Beyazlatma uygulaması sonrası kırmızı şarap ile renklendirilmiş örneklerde polisaj işlemi renklenmeyi önemli ölçüde azalttı $(p<0.001)$ ve polisaj işleminden sonra renklenme açısından gruplar arasında anlamlı bir farklılık bulunamadı $(p>0.05)$. Renklendirme işleminden sonra IIa, Ib, ve IIIb gruplarının $\Delta \mathrm{L}$ değerleri kontrol grubundan anlamlı ölçüde daha düşüktü $(p<0.05)$. Polisaj işleminden sonra gruplar arasında $\Delta L$ değerleri önemli bir farklılık göstermedi ( $p>0.05)$.

Tablo 2. Renklendirme işleminden sonra (T1) ve polisaj işleminden sonra (T2) $\Delta \mathrm{E}$ ve $\Delta \mathrm{L}^{\prime}$ nin ortalama değerleri ve standart sapmaları.

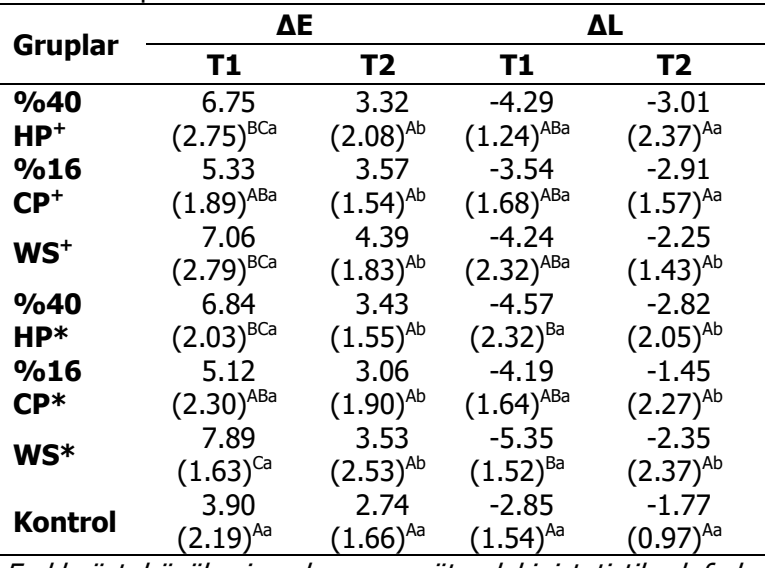

Farklı üst büyük simgeler aynı sütundaki istatistiksel farkı, küçük simgeler ise aynı satırdaki istatistiksel farkı göstermektedir. +: beyazlatmadan hemen sonra, *: beyazlatmadan 48 saat sonra, WS: whitestrips.

\section{TARTIŞMA}

Bu çalışmada, \%40 HP ofis tipi ve \% $16 \mathrm{CP}$ ev tipi beyazlatma ajanlarının dişleri beyazlatmada \%9 HP içerikli striplerden daha fazla etkili olduğu bulundu. Daha önce yapılmış bir çalışmada beyazlatma ajanının konsantrasyonu ve dişe olan temas süresinin beyazlatma derecesi üzerinde önemli etkiye sahip olduğu bildirilmiştir. ${ }^{16}$ Buna karşlık, Matis ve arkadaşları ${ }^{17}$ beyazlatma ajanlarının konsantrasyonunun ve dişe temas süresinin etkili olmadığını bildirmişlerdir. Bu çalışmanın sonuçları beyazlatma ajanının konsantras- yonu ve dişe olan temas süresinin beyazlatma üzerinde önemli etkiye sahip olduğunu gösterdi. Daha kısa temas süreli (toplam 120 dakika) ancak daha yüksek konsantrasyona (\%40 HP) sahip olan ofis tipi beyazlatma, düşük konsantrasyonlu (\%16 CP ve $\sim \% 5,4 \mathrm{HP}$ ) ve uzun temas süresi (toplam 56 saat) ile uygulanan ev tipi beyazlatma ile benzer beyazlatma etkinliği göstermiştir. Bu sonuç yüksek ve düşük konsantrasyon da beyazlatma ajanının benzer etkiye sahip olduğunu söyleyen Sulieman ve arkadaşları'nın ${ }^{18}$ in vitro bulguları ile tutarlıdır. Aynı çalışmada yüksek konsantrasyona sahip ajanların daha hızlı beyazlatma sağladığı bildirilmiştir.

Önceki çalışmalarda beyazlatma sonrası mine yüzeyinde önemli değişiklikler olduğu bildirilmiştir. ${ }^{19-21}$ Hegedus ve arkadaşlar ${ }^{22} \% 10^{\prime}$ luk CP jel ve \%30'luk HP jel ile 28 saatlik tedavi sonrası mine yüzeylerini Atomic Force Mikroskop (AFM) kullanarak incelemiş ve mine yüzeylerinde değişiklikler tespit etmişlerdir. \%30' luk HP ile beyazlatılan örneklerde yüzey değişikliklerini daha belirgin bulmuşlardır. Başka bir çalışmada beyazlatmanın neden olduğu yüzey değişikliklerinin dışsal renklenmeye karşı duyarlılığı arttırdığı bildirilmiştir. ${ }^{23}$ Bazı araştırmacılar beyazlatma sonrası şarap renklenmesine karşı dişlerin duyarlıı̆ı̆ının arttığını belirtmiştir. $^{24,25}$ Bizim sonuçlarımı beyazlatma süresi ne olursa olsun \%40'lık HP ve \%9.5'lik HP (strip) ajanlarının, \%16'ık CP (\% 5.4 HP) ajanı ile kıyaslandığında beyazlatma uygulanmamış dişlere göre diş yüzeylerinin daha fazla renklenmesine neden olduğunu gösterdi. Beyazlatma ajanlarının konsantrasyonuna ek olarak pH değerleri de farklıydı. Beyazlatma tedavileri boyunca mineral kaybına neden olan mekanizma tam olarak belli değildir. Beyazlatma ajanlarının pH'ı mine yüzeylerinde mineral kaybı oluşmasında önemli rol oynayabilir. Daha düşük pH'a sahip beyazlatma ajanları kullanıldığında önceki çalışmalarda mine yüzeylerinde ciddi değişimler meydana geldiği gözlendi ve $\mathrm{pH}$ 5.2 'nin altına düştüğünde minede demineralizasyon gerçekleşti. ${ }^{5,26} \mathrm{Bu}$ çalışmada striplerin $\mathrm{pH}^{\prime \prime}$ diğer beyazlatma ajanlarından daha düşüktü ve beyazlatma stripleri beyazlatma uygulanmamış dişlere kıyasla daha fazla renklenme oluşmasına neden oldu. Fakat stripler ile renklenme beyazlatmadan hemen sonra Opalescence PF ve Opalescence Boost ile istatistiksel olarak benzerdi.

Daha önce bildirildiği gibi diş renklenmesine karşı duyarlıık yalnızca yüzey pürüzlülüğüyle ilgili de-

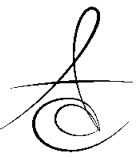


ğildir. Beyazlatma sonrası mine yüzeyleri üzerinde oluşan düzensizlikler, geçirgenlikteki değişiklikler, su emme oranı ve minenin içeriği renklenmede büyük bir role sahiptir. ${ }^{24}$ Bu çalışmada beyazlatma sonrası örnekler 48 saat boyunca yapay tükürük içinde bekletildi. Önceki bir çalışma beyazlatılmış örneklerin tükürük içinde uzun süre saklanmasının renklenmeyi önleyebileceği ve mineral kaybını tersine çevirebileceğini ileri sürmüştür. ${ }^{14}$ Ancak bu çalışmada dişlerin 48 saat boyunca tükürük içinde bekletilmesi dişlerin renklenmeye karşı duyarlıı̆ııı etkilemedi. Yapay tükürük inorganik kalsiyum ve fosfat içerir ama koruyucu tükürük film tabakası oluşturabilen fosfoprotein ve glikoprotein gibi organik bileşenleri içermez. ${ }^{27}$ Tükürük pelikülleri diş yüzeylerini kaplayabilir ve asit erozyonu nedeniyle oluşan demineralizasyonu engelleyebilir. ${ }^{28}$

Beyazlatma sırasında ve sonrasında dişlerin renk stabilitesi büyük oranda hastaların beslenme alışkanlıklarına bağlıdır. ${ }^{29}$ Önceki bir çalışmada düşük pH'a sahip yüksek pigment içerikli içeceklerin dişlerin boyanmasına ve diş yapılarında demineralizasyona neden olduğu bildirilmiştir. ${ }^{30}$ Başka bir çalışmada renklenmeye karşı dişlerin duyarlılığı beyazlatma sonrası bekleme prosedüründen daha ziyade hastanın tüketmiş olduğu içecek tipinin daha etkili olduğu belirtilmiştir. ${ }^{13} \mathrm{Bu}$ renklenmenin bazıları temizlenme veya polisaj ile kaldırılabilen kısa süreli ve geri dönüşümlüdür. ${ }^{31}$ Bu çalışmada beyazlatma sonrası kırmızı şarap içinde bekletilen dişlere polisaj uygulandıktan sonra diş yüzeyleri üzerinde renklenme önemli ölçüde azalmıştır. Polisaj sonrası dişlerin boyanması açısından gruplar arasında önemli bir farklılık bulunamadı. Azer ve arkadaşları ${ }^{32}$ beyazlatma uygulanmış dişlerin renklenmeye karşı daha duyarlı olduğunu bildirmiş ve gıda pigmentlerinin beyazlatılış dişlerde içsel renklenme (polisaj sonrası) oluşturmadığını göstermiş̧ir.

Diş renklenmesi standart diş renk skalası ile subjektif olarak veya spektrofotometre, kolorimetre ve dijital renk analizi ile objektif olarak değerlendirilebilir. Objektif yöntemler, araştırma amaçları açısından özellikle tercih edilebilir çünkü sonuçlar subjektif yöntemlerden daha doğrudur. ${ }^{33}$ Çeşitli renk eşleştirme cihazları klinik kullanım için mevcuttur. Bu çalışmada renk ölçümü için kontak spektrofotometre kullanıldı.

\section{SONUÇLAR}

Bu çalışmanın sınırları içerisinde aşağıdaki sonuçlara varılabilir:
1. Ev ve ofis tipi beyazlatma, dişleri beyazlatmada striplere göre daha etkiliydi.

2. Ofis tipi ve beyazlatma stripleri ile yapılan beyazlatmanın ardından kırmızı şarabın sebep olduğu renk- lenme kontrol grubuyla karşılaştırıldığında ev tipi beyazlatma sonrası renklenmeye göre daha yüksekti.

3. Beyazlatmadan sonra renklenmiş örneklere yapılan polisaj işlemi renklenmeyi önemli derecede azalttı.

\section{KAYNAKLAR}

1. Kwon SR, Oyoyo U, Li Y. Effect of light activation on tooth whitening efficacy and hydrogen peroxide penetration: an in vitro study. J Dent 2013;41 Suppl 3:e39-45.

2. Mielczarek $A$, Klukowska $M$, Ganowicz $M$, Kwiatkowska A, Kwasny M. The effect of strip, tray and office peroxide bleaching systems on enamel surfaces in vitro. Dent Mater 2008;24:1495-500.

3. Haywood VB. Considerations and variations of dentist-prescribed, home-applied vital toothbleaching techniques. Compend Suppl 1994:S61621.

4. Joiner A. The bleaching of teeth: a review of the literature. J Dent 2006;34:412-9.

5. Joiner A. Review of the effects of peroxide on enamel and dentine properties. J Dent 2007;35:889-96.

6. Karadaş $M$, Nilgün $S$. Vital dişlerde beyazlatma. Atatürk Üniv. Diş Hek Fak. Derg 2014; supplement 9:126-35.

7. Pinto CF, Oliveira R, Cavalli V, Giannini M. Peroxide bleaching agent effects on enamel surface microhardness, roughness and morphology. Braz Oral Res 2004;18:306-11.

8. Oltu U, Gurgan S. Effects of three concentrations of carbamide peroxide on the structure of enamel. J Oral Rehabil 2000;27:332-40.

9. Perdigao J, Francci C, Swift EJ, Jr., Ambrose WW, Lopes M. Ultra-morphological study of the interaction of dental adhesives with carbamide peroxide-bleached enamel. Am J Dent 1998;11:291-301.

10. Dietschi $D$, Rossier $S$, Krejci I. In vitro colorimetric evaluation of the efficacy of various bleaching methods and products. Quintessence Int 2006;37:515-26. 
11. Watts A, Addy M. Tooth discolouration and staining: a review of the literature. $\mathrm{Br}$ Dent $\mathrm{J}$ 2001;190:309-16.

12. Azer SS, Hague AL, Johnston WM. Effect of $\mathrm{pH}$ on tooth discoloration from food colorant in vitro. J Dent 2010;38 Suppl 2:e106-9.

13. Pirolo R, Mondelli RF, Correr GM, Gonzaga CC, Furuse AY. Effect of coffee and a cola-based soft drink on the color stability of bleached bovine incisors considering the time elapsed after bleaching. J Appl Oral Sci 2014;22:534-40.

14. Spalding M, Taveira LA, de Assis GF. Scanning electron microscopy study of dental enamel surface exposed to $35 \%$ hydrogen peroxide: alone, with saliva, and with $10 \%$ carbamide peroxide. J Esthet Restor Dent 2003;15:154-64.

15. Borges AB, Yui KC, D'Avila TC, Takahashi CL, Torres $\mathrm{CR}$, Borges $\mathrm{AL}$. Influence of remineralizing gels on bleached enamel microhardness in different time intervals. Oper Dent 2010;35:180-6.

16. Heymann HO. Tooth whitening: facts and fallacies. Br Dent J 2005; 198: 514.

17. Matis BA, Cochran MA, Franco M, Al-Ammar W, Eckert GJ, Stropes $M$. Eight in-office tooth whitening systems evaluated in vivo: a pilot study. Oper Dent 2007;32:322-7.

18. Sulieman M, MacDonald E, Rees JS, Addy M. Comparison of three in-office bleaching systems based on $35 \%$ hydrogen peroxide with different light activators. Am J Dent 2005;18(3):194-7.

19. Bitter NC, Sanders JL. The effect of four bleaching agents on the enamel surface: a scanning electron microscopic study. Quintessence Int 1993; 24: 817-24.

20. Flaitz CM, Hicks MJ. Effects of carbamide peroxide whitening agents on enamel surfaces and carieslike lesion formation: an SEM and polarized light microscopic in vitro study. ASDC J Dent Child 1996;63:249-56.

21. Tezel H, Korkut ZO, Dalgar H, Özata F. \%38'lik hidrojen peroksit içeren beyazlatma ajanının mine yüzeyinden kalsiyum iyonu çözülmesine etkisi. EÜ Dişhek Fak Derg 2004; 25: 145-9.

22. Hegedus C, Bistey T, Flora-Nagy E, Keszthelyi G, Jenei $A$. An atomic force microscopy study on the effect of bleaching agents on enamel surface. J Dent 1999;27:509-15.
23. Dahl JE, Pallesen U. Tooth bleaching--a critical review of the biological aspects. Crit Rev Oral Biol Med 2003; 14:292-304.

24. Berger SB, Coelho AS, Oliveira VA, Cavalli V, Giannini M. Enamel susceptibility to red wine staining after $35 \%$ hydrogen peroxide bleaching. J Appl Oral Sci 2008;16:201-4.

25. Cortes G, Pini NP, Lima DA, Liporoni PC, Munin E, Ambrosano GM, Aguiar FH, Lovadino JR. Influence of coffee and red wine on tooth color during and after bleaching. Acta Odontol Scand 2013;71:1475-80.

26. Shannon H, Spencer P, Gross K, Tira D. Characterization of enamel exposed to $10 \%$ carbamide peroxide bleaching agents. Quintessence Int 1993;24:39-44.

27. Hosoya N, Honda K, Iino F, Arai T. Changes in enamel surface roughness and adhesion of Streptococcus mutans to enamel after vital bleaching. J Dent 2003;31:543-8.

28. Hannig $M$, Balz $M$. Influence of in vivo formed salivary pellicle on enamel erosion. Caries Res 1999;33:372-9.

29. Attia ML, Aguiar FH, Mathias P , Ambrosano GM, Fontes CM, Liporoni PC. The effect of coffee solution on tooth color during home bleaching applications. Am J Dent 2009;22(3):175-9.

30. Ren YF, Amin A, Malmstrom H. Effects of tooth whitening and orange juice on surface properties of dental enamel. J Dent 2009;37:424-31.

31. Joiner A. Review of the extrinsic stain removal and enamel/dentine abrasion by a calcium carbonate and perlite containing whitening toothpaste. Int Dent J 2006;56:175-80.

32. Azer SS, Hague AL, Johnston WM. Effect of bleaching on tooth discolouration from food colourant in vitro. J Dent 2011;39 Suppl 3:e52-6.

33.Braun A, Jepsen S, Krause F. Spectrophotometric and visual evaluation of vital tooth bleaching employing different carbamide peroxide concentrations. Dent Mater 2007;23:165-9.

\section{Yazışma Adresi}

Yrd.Doç.Dr. Muhammed KARADAŞ

Recep Tayyip Erdoğan Üniversitesi

Diş Hekimliği Fakültesi

Diş Hastalıkları ve Tedavisi AD - RİZE e-mail: muhammet.2005@hotmail.com 